\title{
Fungal Rhinosinusitis: Clinicopathological Study of 10 Years
}

\author{
Archana Laxman Khade ${ }^{1 *}$, Manisha S Khare ${ }^{1}$, Uma M Tendolkar² and Felice Faizal ${ }^{1}$ \\ 'Department of Pathology, HBT Medical college and Dr. R.N.Cooper Municipal General Hospital, Juhu, Vile Parle (West), Mumbai ,India \\ ${ }^{2}$ Department of Microbiology, LTMMC and LTMGH, Sion, Mumbai 400022, India
}

\begin{abstract}
Background: To study clinicopathological correlation of fungal infections of nose and paranasal sinuses, to classify them and correlate with fungal culture.

Methods: A Retrospective study of biopsy specimens from nose and paranasal sinuses, diagnosed as fungal rhinosinusitis (FRS) on histology, over a ten year period from January 2002 to October 2012, was carried out. The detailed clinical history was collected from clinical record and culture reports were collected whenever available. The tissues were studied with Haematoxylin and Eosin stain (H\&E) Gomori Methenamine silver (GMS) \& Periodic acid Schiff (PAS) stain. The sinusitis was classified based on histological features.

Results: Total 30 cases of fungal rhinosinusitis were studied. Age ranged between 12 to 82 years. Maximum incidence was seen in 5 th and 6th decade with equal sex distribution. Paranasal sinuses were more commonly involved by fungal infections than nasal cavity. Nasal obstruction and rhinorrhea were the common presenting symptoms. Out of 30 cases, 12 were immunocompetent. 7 cases were of noninvasive FRS which included $1(3.33 \%)$ case of saprophytic fungal infestation, $3(10 \%)$ cases of fungal ball, and 3 (10\%) cases of allergic fungal rhinosinusitis. Invasive FRS constitutes 23 cases, which included 2 (6.67\%) cases of chronic granulomatous invasive FRS, 7 (23.33\%) cases of chronic invasive FRS, and $14(46.67 \%)$ cases of acute fulminant FRS. Invasive FRS was characterized by extensive necrosis with or without granulomatous inflammation. Only 9 out of the 13 fungal cultures available correlated with the histomorphology.
\end{abstract}

Conclusion: FRS should be suspected in nasal biopsies showing extensive necrosis in immunocompromised individuals. Microbiological culture is must for species identification.

Keywords: Fungal Rhinosinusitis, Nose, Paranasal Sinuses, Culture

\section{Introduction}

Although fungal infection of the nose and paranasal sinuses is uncommon, its incidence has increased in the recent years. This change is mainly due to international traffic and opportunistic infection as a consequence of use of powerful cytotoxic drugs, steroids and antibiotic therapy. ${ }^{[1]}$ Most of the fungal infections are noninvasive or benign except when they occur in immunocompromised individuals. Many common saprophytic organisms may become pathogenic producing diseases in immunocompromised patients eg. uncontrolled diabetes. ${ }^{[1]}$ Although commonly seen in immunocompromised individuals, fungal rhinosinusitis (FRS) is seen in immunocompetent individuals also.

There is still controversy regarding the classification and the diagnostic criteria of FRS. Many authors have described five categories, but Chakravarti et at have ${ }^{[2]}$ described six categories, based on its histological features and classified them into noninvasive FRS: saprophytic fungal infection, allergic FRS, fungal ball (mycetoma) and invasive FRS: chronic granulomatous invasive (indolent) fungal rhinosinusitis, chronic invasive fungal rhinosinusitis, and acute necrotizing (fulminant) fungal rhinosinusitis.

\section{Methods}

A Retrospective study of 30 cases of histologically diagnosed fungal rhinosinusitis (FRS) was carried out over a ten year period from January 2002 to October 2012. These include biopsy specimens from nose and paranasal sinuses. The inadequate samples and those from nasopharynx were excluded from the study.

The paraffin blocks of histologically diagnosed cases were retrieved and stained with Haematoxylin and Eosin stain $(\mathrm{H}$ \& E), Gomori Methenamine silver (GMS) \& Periodic acid Schiff stain(PAS).The clinical details, radiological findings and fungal culture reports were obtained from respective departments.

The histological features were reviewed along with the type of fungus grown in the culture or identified by the morphological characteristics of fungus. Slender septate hyphae with acute angle branching were diagnosed as aspergillus, Broad aseptate hyphae with irregular branching were diagnosed as Zygomycetes sp., and Pseudohyphae with budding yeast forms were diagnosed as Candida sp. 


\section{Results}

During the study period total 219 samples from nose and paranasal sinuses were recieved, out of these $30(13.70 \%)$ cases were of fungal rhinosinusitis.

The patient's age ranged from 12 to 82 years. Most common age group affected was $5^{\text {th }}$ and $6^{\text {th }}$ decade with no sex predilection. Out of 30 cases of fungal infections, nasal cavity was involved in $14(46.67 \%)$ cases and paranasal sinuses in $16(53.33 \%)$ cases. In the paranasal sinuses, most common sinus involved was maxillary in 13 $(81.25 \%)$ cases, followed by ethmoid sinus in $9(56.22 \%)$ cases, sphenoid sinus in $2(12.50 \%)$ cases. Multiple sinuses involvement was seen in 9 cases.

In clinical features, nasal obstruction was the most common symptom seen in $24(80 \%)$ cases. $20(66.66 \%)$ patients had rhinorrhea. Ocular symptoms in the form of decreased vision, epiphora, and orbital pain were seen in $11(36.66 \%)$ cases. Nasal mass was seen in $9(30 \%)$ cases, headache in $8(26.66 \%)$ cases, epistaxsis in $2(6.66 \%)$ cases and CNS symptoms in the form of altered sensorium in $1(3.33 \%)$ case.
Out of 30 cases, $14(44.67 \%)$ patients were immunocompromised and had diabetes mellitus. 12 (40\%) patients were immunocompetent and immune status of patient was not known in 4 (13.33\%) cases.

Histologically, aspergillus species was identified in 15 $(50 \%)$ cases, Mucor in $14(46.67 \%)$ cases and candida in $1(3.33 \%)$ case.

These 30 cases were classified according to criteria described by Chakrabarti et al. into

I) Noninvasive fungal rhinosinusitis 7 (23.33\%) cases, which included $1(3.33 \%)$ case of saprophytic fungal infection, $3(10 \%)$ cases of fungal ball/mycetoma and $3(10 \%)$ cases of allergic fungal rhinosinusitis (AFRS).

II) Invasive fungal rhinosinusitis $23 \quad(76.67 \%)$ cases, which included $2(6.67 \%)$ cases of chronic granulomatous invasive fungal rhinosinusitis, 7 $(23.33 \%)$ of chronic invasive fungal rhinosinusitis and $14(46.67 \%)$ cases of acute fulminant fungal rhinosinusitis.

Results are shown in Table No.1

Table No.1

\begin{tabular}{|c|c|c|c|c|c|c|}
\hline \multirow{2}{*}{$\begin{array}{l}\text { Categories } \\
\text { Parameters }\end{array}$} & \multicolumn{3}{|c|}{ Noninvasive fungal rhinosinusitis $n=7$} & \multicolumn{3}{|c|}{ Invasive fungal rhinosinusitis $(n=23)$} \\
\hline & $\begin{array}{c}\text { Saprophytic FRS } \\
(n=1)\end{array}$ & Fungal ball $(n=3)$ & AFRS $(n=3)$ & $\begin{array}{c}\text { Chronic } \\
\text { granulomatous } \\
\text { FRS }(n=2)\end{array}$ & $\begin{array}{l}\text { Chronic invasive } \\
\text { FRS }(n=7)\end{array}$ & $\begin{array}{l}\text { Acute invasive } \\
\text { FRS }(n=14)\end{array}$ \\
\hline Mean Age & 60 years & $4^{\text {th }}$ decade & $2^{\text {nd }}$ decade & $4^{\text {th }}$ decade & $3^{\text {rd }}$ and $4^{\text {th }}$ & $5^{\text {th }} \& 6^{\text {th }}$ \\
\hline Sex M:F & Female & $1: 2$ & $2: 1$ & $1: 1$ & $3: 4$ & $8: 6$ \\
\hline $\begin{array}{l}\text { Clinical } \\
\text { features }\end{array}$ & $\begin{array}{c}\text { Rhinorrhea Nasal } \\
\text { blockage }\end{array}$ & $\begin{array}{c}\text { Nasal polyp, } \\
\text { headache, orbital } \\
\text { pain }\end{array}$ & $\begin{array}{l}\text { Nasal polyp, } \\
\text { rhinorrhea }\end{array}$ & Nasal blockage & $\begin{array}{c}\text { Nasal Blockage, } \\
\text { rhinorrhea, } 3 \text { had obital } \\
\text { apex syndrome }\end{array}$ & $\begin{array}{c}\text { Nasal and PNS } \\
\text { polyposis, rhinooccular } \\
\text { symptoms in } 7 \text { cases }\end{array}$ \\
\hline $\begin{array}{l}\text { Immune } \\
\text { status }\end{array}$ & Not available & Immunocompetent & Immunocompetent & Immunocompetent & $\begin{array}{l}\text { Immunocompetent-5, } \\
\text { immunocompromised-1, } \\
\text { status not available }-1\end{array}$ & $\begin{array}{c}\text { immunocompromised-11 } \\
\text { imunocompetant-1, } \\
\text { status not available-2 }\end{array}$ \\
\hline Histology & $\begin{array}{l}\text { Superficial colonization } \\
\text { of nasal mucosa } \\
\text { with PAS positive } \\
\text { pseudohyphae and } \\
\text { yeast of candida with } \\
\text { bacterial colonies. } \\
\text { (Figure no.1 A) }\end{array}$ & $\begin{array}{l}\text { The tightly packed } \\
\text { septate fungal } \\
\text { hyphae appearing } \\
\text { pale in the centre, } \\
\text { with morphology } \\
\text { more apparent at } \\
\text { the periphery. The } \\
\text { adjoining mucosa } \\
\text { showed a mixed } \\
\text { inflammatory } \\
\text { infiltrate. On H \& E } \\
\text { and GMS hyphae of } \\
\text { aspergillus species } \\
\text { was seen. (Figure } \\
\text { no.1B) }\end{array}$ & $\begin{array}{l}\text { Allergic mucin with } \\
\text { variable intensity } \\
\text { of staining having } \\
\text { cracks and folds } \\
\text { with abundant } \\
\text { eosinophils. The } \\
\text { mucosa was } \\
\text { oedematous with } \\
\text { a few scattered } \\
\text { fragmented septate } \\
\text { fungal hyphae of } \\
\text { aspergillus seen } \\
\text { on H \& E and } \\
\text { GMS stain .(Figure } \\
\text { no.1C\&D) }\end{array}$ & $\begin{array}{c}\text { granulomatous } \\
\text { inflammation with } \\
\text { scattered giant cells, } \\
\text { fibrosis, and chronic } \\
\text { lymphoplasmacytic } \\
\text { infiltrate with } \\
\text { eosinophils. GMS stain } \\
\text { in showed slender } \\
\text { septate acute angle } \\
\text { branching hyphae of } \\
\text { aspergillus. } \\
\text { (Figure no.2A\& B) }\end{array}$ & $\begin{array}{l}\text { Microscopy showed } \\
\text { invasive septate, acute } \\
\text { angle branching fungal } \\
\text { hyphae with acute } \\
\text { inflammatory infiltrate } \\
\text { of polymorphs and } \\
\text { foci of necrosis. In all } \\
\text { cases, fungal hyphae } \\
\text { resembling aspergillus } \\
\text { species was noted on } \\
\text { GMS stain. (Figure no. } \\
2 \text { C\&D) }\end{array}$ & $\begin{array}{c}\text { Microscopy showed } \\
\text { extensive areas of } \\
\text { coagulative necrosis, } \\
\text { inflammatory infiltrate } \\
\text { with or without } \\
\text { angioinvasion by fungus. } \\
\text { H \& E and GMS stain, } \\
\text { fungal morphology was } \\
\text { broad aseptate hyphae } \\
\text { with irregular branching, } \\
\text { consistent with mucor. } \\
\text { (Figure no .3A\&B) }\end{array}$ \\
\hline Culture & Candida albicans & $\begin{array}{c}\text { Available in only } \\
\text { one cases,- septate } \\
\text { hyphae }\end{array}$ & Not available & Not available & $\begin{array}{l}\text { Available in two - } \\
\text { aspergillus }\end{array}$ & $\begin{array}{l}\text { Mucor-1, Rhizopus-6, } \\
\text { aspergillus-2 }\end{array}$ \\
\hline
\end{tabular}




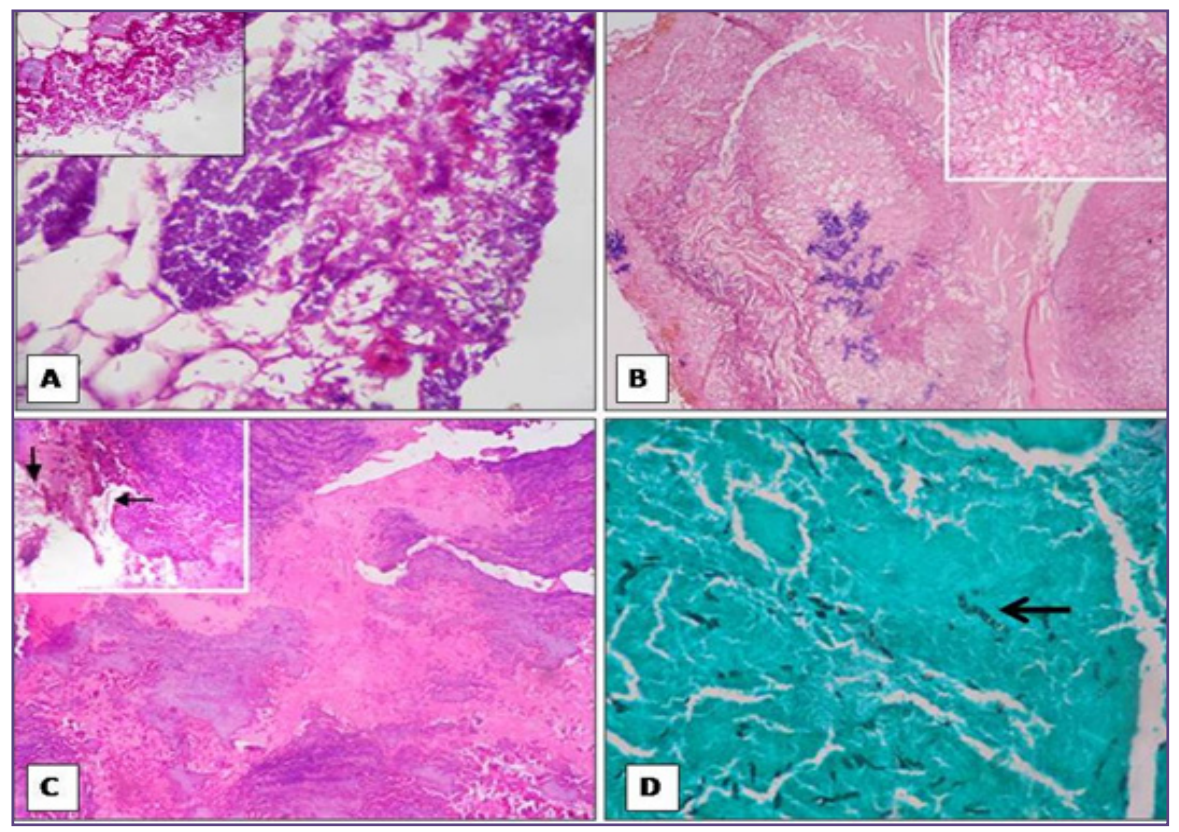

Fig. 1:A): Saprophytic fungal infection: Yeast and pseudohyphae of candida (H\& E, 100X).Inset: PAS highlighting Yeast and pseudohyphae of candida.B) Fungal ball: The tightly packed septate fungal hyphae appearing pale in the centre, with morphology more apparent at the periphery. (H\&E 100X) Inset: septate acute angle branching fungal hyphae of aspergillus are seen (H\& E, 400X)C) Allergic fungal rhinosinusitis: Allergic mucin with variable intensity of staining having cracks and folds with abundant eosinophils. (H\&E 100X) Inset: few scattered fragmented septate fungal hyphae of aspergillus. (H\&E 400X)D)Allergic fungal rhinosinusitis: scattered fragmented septate fungal hyphae of aspergillus .(GMS 400X).

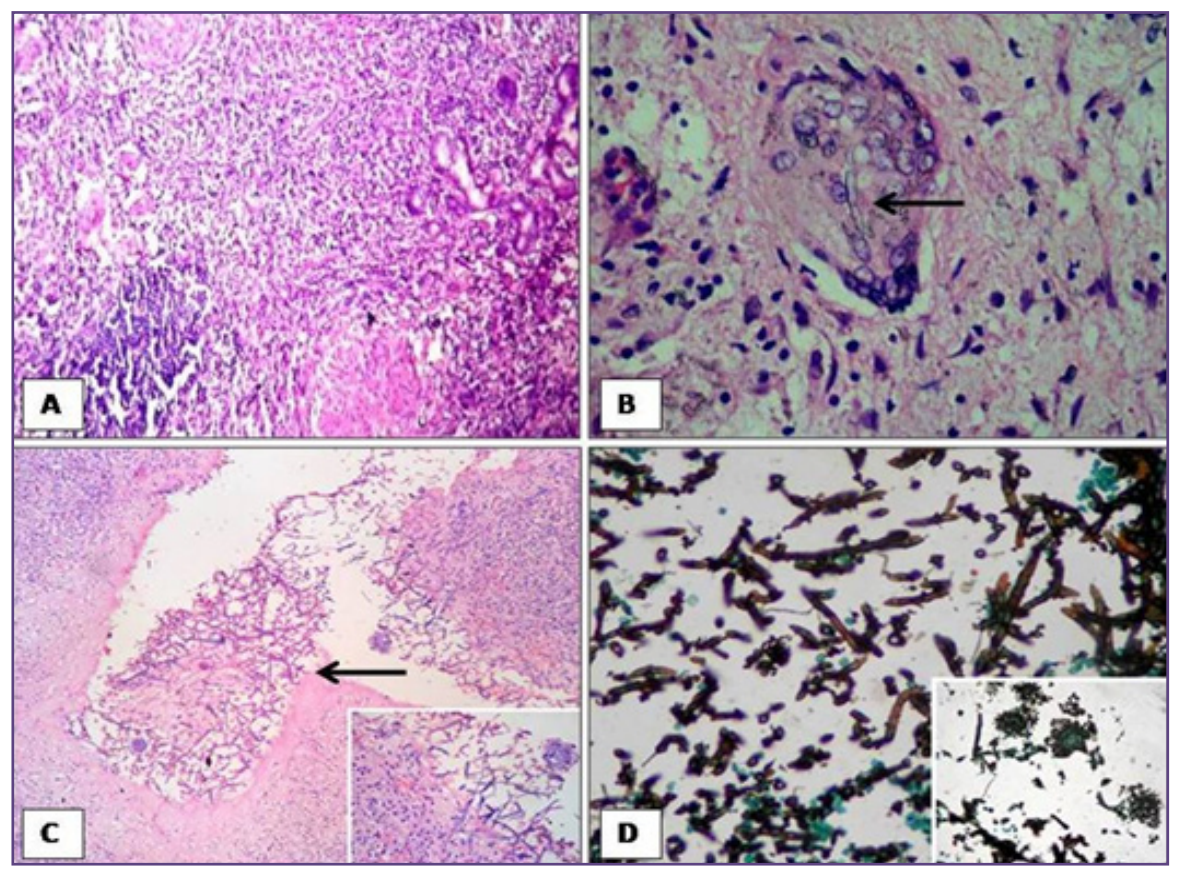

Fig. 2: A) Chronic granulomatous fungal rhinosinusitis: granulomatous inflammation with scattered giant cells, fibrosis, and chronic lymphoplasmacytic infiltrate with eosinophils. (H\&E 100X)B) Chronic granulomatous fungal rhinosinusitis: single giant cell showing fungal hyphae $(\mathrm{H} \& \mathrm{E} 400 \mathrm{X}) \mathrm{C})$ Chronic invasive fungal rhinosinusitis: invasive septate, acute angle branching fungal hyphae with acute inflammatory infiltrate of polymorphs and foci of necrosis. (H\&E 100X)D) Chronic invasive fungal rhinosinusitis: Narrow acute angle branching septate hyphae of aspergillus. (GMS 400X)Inset:Characterestics fruting head of aspergilus (GMS 400X) 


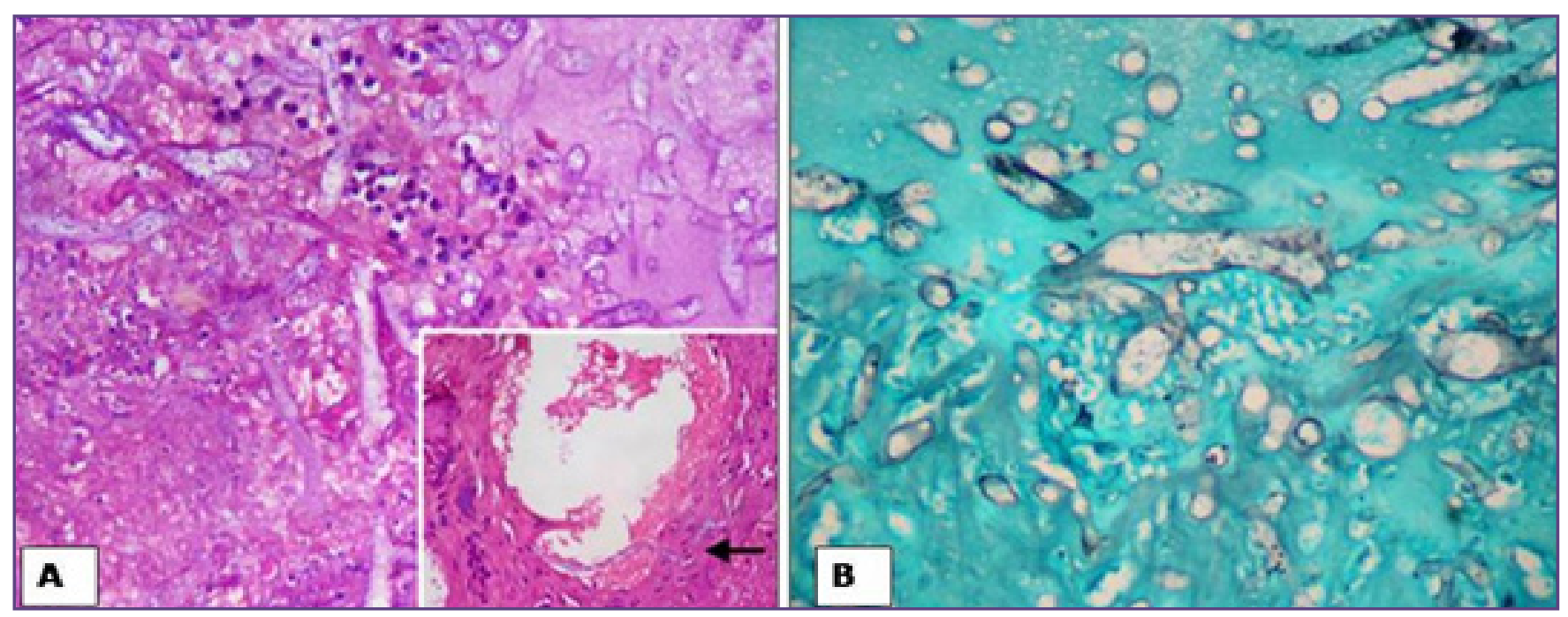

Fig. 3:A) Acute fulminant fungal rhinosinusitis: showing area of necrosis with broad aseptate fungal hyphae of mucor. (H\& E 400X)Inset: angioinvasion by fungal hyphae of mucor. (H\&E 400X)B)Acute fulminant FRS showing broad aseptae hyphae of mucor. (GMS 400X).

\section{Discussion}

Fungal rhinosinusitis is considered to be uncommon condition but its incidence is increasing particularly in immunocompromised individuals. It comprises variety of disease process which varies in presentation and histological appearance. Clinically FRS can be acute (aggresive) and chronic (indolent). ${ }^{[2,3]}$ Pathologically based on histomorphological features it is classified into noninvasive and invasive. In current study, we present a cohort of 30 cases of fungal rhinisinusitis. The majority of patients that we observed, were those of invasive FRS (76.67\%) with acute fulminant FRS (46.67\%) being the most common. Similar observations were seen in study performed by Challa et al. ${ }^{[4]}$ which showed invasive FRS in $75 \%$ of cases. However other studies performed in India, showed more number of noninvasive cases than invasive. Das et al. ${ }^{[5]}$ observed noninvasive FRS in $60 \%$ of 284 cases and invasive in $36 \%$. Michael et al ${ }^{[6]}$ studied 211 cases of culture positive FRS cases and observed $63 \%$ of allergic FRS. Montone et al ${ }^{[7]}$ review 400 cases of FRS with noninvasive FRS seen in $87.25 \%$. According to Montone et al. this geographic diversity may be due to different climates and environmental factors with different means of fungal exposure. Reason for more number of acute FRS could be due to increased incidence of diabetes with overall poor control, and our institute being a tertiary care referral centre for a local practitioner and primary health centre, only critical cases are referred here.

Though, none of the above authors had described saprophytic fungal infection in their studies, we had one such case seen in immunocompetent individual.
There were 3 cases of noninvasive FRS presented as a fungal ball. It is characterized by extramucosal accumulation of fungal hyphae within the sinus cavity. Maxillary sinus was most commonly affected. Culture report was available in only one case which showed septate fungal hypahe. AFRS was seen in 3 cases in our study. It is an increasingly recognized type of chronic noninvasive fungal rhinosinusitis, representing an allergic/ hypersensitivity response to the presence of extramucosal fungi within the sinus cavity. ${ }^{[8]}$ The common causes of allergic fungal sinusitis are the dematiaceous hyphomycetes including curvularia sp., bipolaris sp., pseudallescheria boydii, and the hyaline hyphomycetes such as aspergillus sp. and fusarium sp. ${ }^{[8]}$ AFRS was diagnosed on basis of pathological criteria's described by deShazo RD et al and Schubert MS. ${ }^{[3,9]}$ Histologically, the cases which showed characteristic allergic mucin, eosinophills with fungal hyphae were diagnosed as AFRS. Aspergillus species was causative organism in all our cases, however fungal cultures were not available for confirmation.

Chronic granulomatous invasive fungal rhinosinusitis also called indolent fungal sinusitis. Patients appear to be immunocompetent and are infected almost exclusively with aspergillus flavus. Clinically the patients present with a syndrome of chronic rhinosinusitis with proptosis and occasionally headache. ${ }^{[8]}$

In our study, chronic granulomatous invasive fungal rhinosinusitis was seen in 2 cases; both were immunocompetent with aspergillus being the causative fungus. 
Chronic invasive fungal rhinosinusitis can be distinguished from other two types of invasive fungal rhinosinusitis by a chronic course, dense accumulation of hyphae, and an association with orbital apex syndrome (extension of fungal infection from ethmoid sinus to the ipsilateral orbit). ${ }^{[8]}$ In our study, 7 cases were of chronic invasive FRS. Out of which 3 presented as orbital apex syndrome and only 2 were immunocompromised. Chronic invasive FRS is usually noted in immunocompromised individual but there has been a reported case in apparently normal, immunocompetent individual. ${ }^{[10.11]}$ Similar observations were made earlier by Michael et $\mathrm{al}^{[6]}$, who proposed that malnutrition in Indian patients may be a contributing factor in such patients. The authors also proposed that patients may not be known diabetics at the time of diagnosis.

Acute necrotizing (fulminant) fungal rhinosinusit is most severe and fatal form and seen usually in immunosuppressed patients. Saprophytic fungi of the order mucorales, including species under rhizopus, rhizomucor, absidia, mucor, are usual etiological agents. The lesion starts as a nasal eschar spreading through mucosa into juxtaposed soft tissues and bone. ${ }^{[8]}$ There were 14 cases of acute fulminant FRS and was the most common fungal infection found in our study. Out of 14 cases, 11 patients were immunocompromised had diabetes mellitus and 1 patient was immunocompetent but he was a known case of leprosy on treatment and had history of dental extraction one month back. All of our cases showed mucor as causative fungus on $\mathrm{H} \& \mathrm{E}$ and the special stains.

Mucormycosis is usually noted in immunocompromised individual but there have been reported cases of mucormycosis in apparently normal, immunocompetent individual. ${ }^{[12,13]}$ Mignogna et al. ${ }^{[13]}$ reviewed 81 cases of rhino-orbito-cerebral mucormycosis in immunocompetent patients. According to them, possibility of developing mucor infection in such patients seems to be related to ability of this fungus of attacking the epithelium previously damaged by prior infection, cytotoxic drugs or direct trauma. Also the fungus is capable of secreting several toxins or proteases, which may directly destroy endothelial cells in mucosal membrane. They also hypothesized that chronic local insult such as chronic sinusitis, might be a predisposing factor of mucor infection in immunocompetent or healthy individual.

Culture reports were available which showed aspergillus species in 2 cases. This discrepancy between culture report and histopathological diagnosis in 2 cases could be because; histologically, degenerated hyphae of aspergillus may resemble those of mucor. ${ }^{[14]}$ In presence of extensive degeneration or necrosis of the fungal mycelium the differential diagnosis between aspergillus and mucor is very difficult on microscopic features alone.

\section{Conclusion}

Fungal rhinosinusitis though rare is an aggressive medical condition and needs prompt medical attention and management. Stains for identifying fungal elements should be carried out on all nasal and paranasal biopsies especially showing necrosis. Morphological identification of fungal species may not be accurate and hence correlation with fungal culture is necessary.

\section{References}

1. Friedman I, Osborn DA. Mycotic and parasitic infections. In: Pathology of granulomas and neoplasms of nose and paranasal sinuses. New York: Churchill Livingstone; 1982. $70-81$.

2. Chakrabarti A, Denning DW, Ferguson BJ, Ponikau J, Buzina W, Kita H, et at. Fungal rhinosinusitis: a categorization and definitional schema addressing current controversies. Laryngoscope 2009; 119: 1809-1818.

3. deShazo RD, Chapin K, Swain RE, Fungal sinusitis, New Eng J Med 1997.337 254-259

4. Challa S, Uppin SG, Hanumanthu S et al., "Fungal rhinosinusitis: a clinicopathological study from South India,'European Archives of Oto-Rhino-Laryngology, 2010; 267, 1239-45.

5. Das A, Bal A, Chakrabarti A, Panda N, Joshi K, "Spectrum of fungal rhinosinusitis; Histopathologist's perspective," Histopathology, 2009; 54, 854-859.

6. Michael R, Michael J, Ashbee R, Mathews M, "Mycological profile of fungal sinusitis: an audit of specimens over a 7-year period in a tertiary care hospital in Tamil Nadu," Indian Journal of Pathology and Microbiology, 2008; 51, 493-496.

7. Kathleen T. Montone, Virginia A. Livolsi, Michael D. Feldman, et al., "Fungal Rhinosinusitis: A Retrospective Microbiologic and Pathologic Review of 400 Patients at a Single University Medical Center," International Journal of Otolaryngology, vol. 2012, Article ID 684835, 9 pages, 2012. doi:10.1155/2012/684835

8. Chakrabarti A, Das A, Panda N. Overview of fungal rhinosinusitis. Ind J of Otorhinolaryngol and Head and Neck Surg 2004; 56(4): 251-258.

9. Schubert MS, Allergic fungal sinusitis, Otolaryngol Clin N Am 2004, 37 301-326

10. Mylona S, Tzavara V, Ntai S, Pomoni M, Thanos L. Chronic invasive sinus aspergillosis in an immunocompetent patient: a case report. Dentomaxillofac Radiol. 2007 Feb; 36(2):102-4. 
11. Washburn RG, Kennedy DW, Begley MG, Henderson DK, Bennett JE. Chronic fungal sinusitis in apparently normal hosts. Medicine (Baltimore). 1988 Jul;67(4):231-47

12. Bharathi R, Arya AN. Mucormycosis in an immunocompetent patient. J Oral Maxillofac Pathol 2012; 16: 308-309.

13. Mignogna MD, Fortuna G, Leuci S, Adamo D, Ruppo E, Siano M, et al. Mucormycosis in immunocompetent patients: a case-series of patients with maxillary sinus involvement and a critical review of the literature. Int J Infect Dis 2011; 15 (8): e533-e540.

14. Watts JC, Chandler FW. Aspergillosis. In: Connor DH, Chandler FW, Schwartz DA, Manz HJ, Lack EE, editors. Pathology of infectious diseases. Vol 2. Connecticut; Appleton and Lange: 1997. 933-941.

*Corresponding author:

Dr Archana L Khade, Assistant Professor, Department of Pathology, HBT Medical college and Dr. R.N.Cooper Municipal General Hospital,

Juhu, VileParle (West), Mumbai-400056 India

Phone: +9109404216083 / 08689948700

Email: arck115@gmail.com,

Financial or other Competing Interests: None. 